\title{
PATTERN OF METABOLIC SYNDROME IN CLINICAL PRACTICE
}

\author{
QUAZI TARIKUL ISLAM ${ }^{1}$, MD. AZIZUL HAQUE ${ }^{2}$, ASMSHAWKAT ALI ${ }^{3}$, ARMSAIFUDDIN EKRAM ${ }^{4}$, \\ SULTANA MONIRA HUSSAIN ${ }^{5}$, KHAN ABUL KALAM AZAD ${ }^{6}$, AHMED HOSSAIN $^{7}$
}

\begin{abstract}
:
1068 randomly sampled adult Bangladeshi people were studied during a period of six months from October 2004 to March 2005. It was a randomized, prospective study. Cases that fulfilled two criteria of metabolic syndrome (MetS) were evaluated to see pattern and types of MetS. Out of 1068 patients, 110 (10.3\%) fulfilled the inclusion criteria. 101 (9.4\%) cases were labeled as metabolic syndrome according to NCEP ATP III criteria, 09 cases had only two criteria. 40 cases were male \& 70 cases were female $(M: F=1: 1.8)$. Mean age of patients with was 44.88 , ranging from the age of 20-68 years. Majority (55\%) of the patients were in the age group of 30-49 years. Half of the cases had BMI 30-34.9. Mean body weight of male was $85.9 \mathrm{~kg}$ and of female was $78.2 \mathrm{~kg}$. Mean waist circumference of male was 41.7 inches and of female 40 inches. Mean HDL for male was $38.3 \mathrm{mg} / \mathrm{dL}$ and for female is $40.2 \mathrm{mg} / \mathrm{dL}$. Mean Triglyceride for male was 172.1 and for female was $169.3 \mathrm{mg} / \mathrm{dL}$. Mean total cholesterol for male was 216.7 and for female was $207.6 \mathrm{mg} / \mathrm{dL}$. Mean systolic blood pressure (SBP) for men is $162 \mathrm{~mm} \mathrm{Hg} \&$ diastolic blood pressure (DBP) $99 \mathrm{~mm} \mathrm{Hg}$ and for female mean SBP 155 and DBP $96 \mathrm{~mm} \mathrm{Hg}$. Metabolic syndrome is more prevalent in the 3rd and 4th decade of life in both sexes. It is almost twice common in female than male. Combination of hypertension, obesity \& dyslipidemia comprises nearly $40 \%$ of its presentation.
\end{abstract}

\section{Introduction:}

Metabolic Syndrome (MetS) refers to a clustering of specific cardiovascular disease risk factors whose underlying pathophysiology is thought to be related to insulin resistance. This risk factor clustering, and its association with insulin resistance led investigators to propose the existence of a unique pathophysiological condition- the "metabolic" or "insulin resistance" syndrome. This concept was unified and extended with the landmark publication of Reaven's 1988 Banting Medal award lecture. ${ }^{1}$ Although obesity was not included in Reaven's primary list of disorders caused by insulin resistance, he acknowledged that it, too, was correlated with insulin resistance or hyperinsulinemia, and that the obvious "treatment" for what he termed "syndrome X" was weight maintenance (or weight loss) and physical activity. People with the metabolic syndrome are at increased risk for developing diabetes mellitus and cardiovascular disease as well as increased mortality from cardiovascular disease and all causes. ${ }^{2-4}$ Beyond CVD and type 2 diabetes, individuals with metabolic syndrome seemingly are susceptible to other conditions, notably polycystic ovary syndrome, fatty liver, cholesterol gallstones, asthma, sleep disturbances, and some forms of cancer. ${ }^{5}$

Although there are divergent criteria for the identification of the MetS, they all tend to agree that the MetS core components include obesity, insulin resistance, dyslipidemia, and hypertension. ${ }^{6}$ The first formal definition of the MetS was put forth in 1998 by the World Health Organization (WHO). ${ }^{7}$ The European Group for the Study of Insulin Resistance (EGIR) published a separate set of criteria shortly thereafter. ${ }^{8}$ In 2001, the NCEP: ATP III published a new set of criteria based on common clinical measurements: Waist circumference (WC), blood lipids, blood pressure, and fasting glucose Table-I. ${ }^{9}$

1. Professor and Head, Department of Medicine, Rajshahi Medical College.

2. Resident Physician (Medicine), Rajshahi Medical College Hospital

3. M. Phil Pharmacology (Thesis part) Student, Rajshahi Medical College.

4. Professor of Medicine, Rajshahi Medical College.

5. Research Assistant, Rajshahi Medical College Hospital.

6. Professor of Medicine, Dhaka Medical College.

7. Assistant Professor, Department of Medicine, Dhaka Medical College

Correspondence : Prof. Quazi Tarikul Islam. Professor and Head. Department of Medicine, Rajshahi Medical College.

E-mail: prof.tarik@gmail.com 
Table-I

Criteria for MetS definition:

\begin{tabular}{|c|c|c|}
\hline WHO, $1998^{7}$ & EGIR, $1999^{8}$ & NCEP:ATP III $2001^{10}$ \\
\hline $\begin{array}{l}\text { High insulin levels, IFG or IGT, and two } \\
\text { of the following: } \\
\text { Abdominal obesity: } \\
\text { WHR > 0.9, BMI > } 30 \mathrm{~kg} / \mathrm{m} 2, \mathrm{WC}>37 \\
\text { inches Lipid panel with triglycerides }> \\
150 \mathrm{mg} / \mathrm{dl} \text {, HDL-C }<35 \mathrm{mg} / \mathrm{dl} \mathrm{BP}>140 / \\
90 \mathrm{~mm} \mathrm{Hg}\end{array}$ & $\begin{array}{l}\text { FPG }>6.0 \text { but not DM, BP } \\
\text { e" } 140 / 90, \mathrm{TG}>2 \mathrm{~m} \mathrm{~mol} / \mathrm{l} \\
(180 \mathrm{mg} / \mathrm{dl}), \mathrm{HDL}<1.0 \mathrm{mmol} / \\
\mathrm{l}(40 \mathrm{mg} / \mathrm{dl}), \mathrm{WC}>94 \mathrm{~cm} \mathrm{in} \\
\text { menand }>80 \mathrm{~cm} \text { in women }\end{array}$ & $\begin{array}{l}\mathrm{FPG}>6.0 \mathrm{mmol} / \mathrm{L}, \mathrm{BP} \mathrm{e} 130 / \\
85, \mathrm{TG}>=1.7 \mathrm{mmol} / \mathrm{L}(150 \mathrm{mg} / \\
\mathrm{dl}), \mathrm{HDL} \mathrm{Men}<1.0 \mathrm{mmol} / \mathrm{l} \\
(40 \mathrm{mg} / \mathrm{dl}) \text { Women }<1.3 \mathrm{mmol} / \\
1(50 \mathrm{mg} / \mathrm{dl}), \mathrm{WC}>102 \mathrm{~cm} \mathrm{in} \\
\text { men or }>88 \mathrm{~cm} \text { in women }\end{array}$ \\
\hline
\end{tabular}

WHR: Waist-to-hip ratio; BP: blood pressure; FPG: fasting plasma glucose. WC: Waist Circumference. In 2003, the ADA changed the criteria for IFG tolerance from $>110 \mathrm{mg} / \mathrm{dl}$ to $>100 \mathrm{mg} / \mathrm{dl}$,

The prevalence of the metabolic syndrome as defined by ATP III in our country is unknown. Because the implications of the metabolic syndrome for health care are substantial, we sought to establish the prevalence and pattern of this condition.

\section{Materials \& Methods:}

1068 patients were enrolled for a period of six month (October' 04 - March' 05). NCEP ATP III 2001 criteria were used to diagnose metabolic syndrome in our cohort of population. Patients who had two criteria primarily were included for study. They were thoroughly interviewed as per the protocol and related investigations were done. Three criteria that fulfill the diagnosis of metabolic syndrome are: (i) Abdominal obesity (waist circumference), Men >102 cm (40inch); Women $>88 \mathrm{~cm}$ (35 inch) (ii) Blood pressure, $>130 /$ $\mathrm{mm}$ of $\mathrm{Hg}$ (iii) Fasting blood glucose $>110 \mathrm{mg} / \mathrm{dl}$. All the patients included in this study were above 20 years of age. Patients were excluded who had co-morbidity like CRF, CHD, and taking steroid for some other diseases because that would influence the inclusion criteria of metabolic syndrome. Lipid profile estimation was done after 10 hours fasting by Human $\mathrm{GmbH}$ kit. Blood sugar estimation was done by Human Gumbo kit. Body weight measurement was done by standard weighing measuring machine.

Fiber made simple measuring tape was used to measure abdominal girth. Types of MBI have been classified as follows: A-BMI <24.9; B-BMI 25-29.9; CBMI 30-34.9; D-BMI 35-39.9 and E-BMI > 40. Combination criteria of metabolic syndrome have also been asserted as: DDyO-Diabetes, Dyslipedemia \& Obesity; DHO- Diabetes, Hypertension \& Obesity; DDyHO- Diabetes, Dyslipedemia, Hypertension \& Obesity; DDyH- Diabetes, Dyslipedemia \&
Hypertension; DyHO- Dyslipedemia, Hypertension \& Obesity; and Others (HO-Hypertension, Obesity and HOW-Hypertension, Over weight).

\section{Results:}

Out of 1068 cases 101 (9.4\%) fulfilled three criteria of metabolic syndrome. 09 cases fulfilled only two criteria. 40 cases male $\& 70$ cases female ( $\mathrm{M}: \mathrm{F}=1: 1.8)$. Mean age of patients with $\mathrm{SD}$ is $44.88 \pm 12.28$ ranging from the age of 20-68 years. With the increase in age number of patients increased (Fig.-1). 61 patients (55\%) are between $3 \mathrm{rd}$ and 4 th decade of age. $50 \%$ patients were obese, $22 \%$ moderately obese, only $5 \%$ had severe obesity. $15 \%$ were over weight and $8 \%$ had normal body weight. Table-II shows the patient profile. 35 (38.5\%) patients had DyHO, 25 (27.5\%) patients had DDyH, 22 (24.2\%) patients had DDyHO, 13 (14.3\%) patients had DHO, 6 (6.6\%) patients had DDyO, and 9 (9.9\%) patients had other types (Table-III).

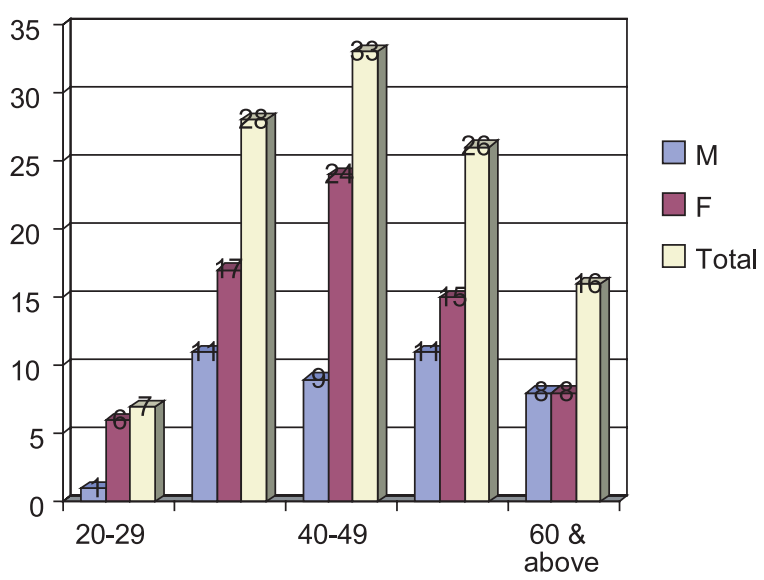

Fig.-1: Shows age specific prevalence of metabolic syndrome in adults 
Table-II

Shows of different parameter of patient profile

\begin{tabular}{lcccc}
\hline Parameters & \multicolumn{2}{c}{ Male } & \multicolumn{2}{c}{ Female } \\
& Mean & SD + & Mean & SD \pm \\
\hline Body weight & 85.95 & 13.57 & 78.22 & 14.58 \\
Waist circumference & 41.67 & 4.35 & 39.97 & 3.91 \\
Total cholesterol & 216.73 & 40.96 & 207.61 & 49.18 \\
LDL & 147.6 & 35.55 & 136.1 & 40.6 \\
HDL & 38.36 & 5.88 & 40.21 & 8.9 \\
TG & 172.17 & 61.83 & 169.38 & 82.22 \\
PPBS & 10.6 & 4.83 & 10.45 & 5.05 \\
Systolic BP & 162 & 20.28 & 155 & 33.87 \\
Diastolic BP & 99 & 10.37 & 96 & 12 \\
FBS & 7.8 & 2.87 & 8.14 & 2.94 \\
\hline
\end{tabular}

Table-III

Patterns of Metabolic syndrome in study population

\begin{tabular}{lcc}
\hline Pattern of MetS & Number & Percentage \\
\hline DyHO & 35 & 38.5 \\
DDyH & 25 & 27.5 \\
DDyHO & 22 & 24.2 \\
DHO & 13 & 14.3 \\
DDyO & 6 & 6.6 \\
Others & 9 & 9.9 \\
\hline
\end{tabular}

\section{Discussion:}

The prevalence of the MetS is increasing to epidemic proportions not only in the United States and the remainder of the urbanized world but also in developing nations and an increasing trend has been observed in Asian countries. ${ }^{11,12}$ Urbanization, modern lifestyle, change of food habit cumulatively contributes for this development of metabolic syndrome. We have applied the NCEP ATP III panel criteria 2002 to assess the prevalence and pattern of metabolic syndrome among Bangladeshi adult. The prevalence of metabolic syndrome is $9.4 \%$ in our study. Prevalence is 1.8 times more in female than male. Prevalence of metabolic syndrome seems to be much lower than some other population. To estimate prevalence of MetS in USA a large scale study was undertaken. Analysis of data was done on 8814 men and women aged 20 years or older from the Third
National Health and Nutrition Examination Survey (1988-1994), a cross-sectional health survey of a nationally representative sample of the noninstitutionalized civilian US population. Prevalence of the metabolic syndrome was defined by ATP III criteria. The unadjusted and age-adjusted prevalence of the metabolic syndrome were $21.8 \%$ and $23.7 \%$, respectively. ${ }^{13}$ The prevalence increased from $6.7 \%$ among participants aged 20 through 29 years to $43.5 \%$ and $42.0 \%$ for participants aged 60 through 69 years and aged at least 70 years, respectively. Mexican Americans had the highest age-adjusted prevalence of the metabolic syndrome (31.9\%). The age-adjusted prevalence was similar for men (24.0\%) and women (23.4\%). However, among African Americans, women had about a 57\% higher prevalence than men did and among Mexican Americans, women had about a 26\% higher prevalence than men did. Using 2000 census data, about 47 million US residents have the metabolic syndrome. ${ }^{13}$

In Finland and Sweden MetS prevalence was studied using WHO definition of MetS. A total of 4,483 subjects aged 35-70 years participating in a large family study of type 2 diabetes in Finland and Sweden (the Botnia study) were included in the analysis of cardiovascular risk associated with the metabolic syndrome. In subjects who had type 2 diabetes $(n=1,697)$, impaired fasting glucose (IFG)/impaired glucose tolerance (IGT) $(n=798)$, or insulin-resistance with normal glucose tolerance (NGT) $(n=1,988)$, the metabolic syndrome was defined as presence of at least two of the following risk factors: 
obesity, hypertension, dyslipidemia, or microalbuminuria. Cardiovascular mortality was assessed in 3,606 subjects with a median follow-up of 6.9 years. In women and men, respectively, the metabolic syndrome was seen in 10 and $15 \%$ of subjects with NGT, 42 and $64 \%$ of those with IFG/IGT, and 78 and $84 \%$ of those with type 2 diabetes. ${ }^{14}$ The risk for coronary heart disease and stroke was increased threefold in subjects with the syndrome $(p<0.001)$. Cardiovascular mortality was markedly increased in subjects with the metabolic syndrome (12.0 vs. $2.2 \%, \mathrm{p}<0.001)$. Of the individual components of the metabolic syndrome, microalbuminuria conferred the strongest risk of cardiovascular death (RR 2.80; $\mathrm{p}=0.002) .{ }^{14}$

Changes in the characteristics of metabolic syndrome in South Korea was assessed between 1998 to 2001.Metabolic syndrome was defined according to NCEP ATP III criteria. The age-adjusted prevalence of metabolic syndrome was significantly higher in the 2001 survey than in 1998 survey ( 28.0 vs. $23.6 \%, \mathrm{P}<$ 0.01 ). This represents an $18.6 \%$ increase in prevalence over 3 years (i.e., $\sim 6 \%$ per annum). ${ }^{15}$

As because metabolic syndrome yet not have an universally acceptable definition for all ethnic class of population so prevalence and different modalities of presentation differs from different ethnic group in a same class for different criteria of definition at different time. To make an absolute conclusion and apprehension of risk of metabolic syndrome is a very difficult task.

\section{Conclusion:}

Metabolic syndrome is not only the problem for the affluent class and for the western countries only. It is a new hidden burden for the Bangladeshi population too. The prevalence of metabolic syndrome in our study is much lower than that of many other populations of the world. A larger population based study is required to find out the magnitude of metabolic syndrome in Bangladeshi population.

\section{References:}

1. Reaven GM. Role of insulin resistance in human disease. Diabetes 1988; 37:1595-1607.

2. Haffner SM, Valdez RA, Hazuda HP, Mitchell BD, Morales PA, Stern MP. Prospective analysis of the insulin-resistance syndrome (syndrome X). Diabetes. 1992;41:715-722.

3. Isomaa B, Almgren P, Tuomi T, et al. Cardiovascular morbidity and mortality associated with the metabolic syndrome. Diabetes Care. 2001;24:683-689).

4. Trevisan M, Liu J, Bahsas FB, Menotti A. Syndrome $\mathrm{X}$ and mortality: a population-based study. Am J Epidemiol 1998;148:958-966.
5. Grundy SM, Brewer HB, Cleeman JP, Smith SC, Lenfant C. Definition of Metabolic Syndrome: Report of the National Heart, Lung, and Blood Institute/ American Heart Association Conference on Scientific Issues Related to Definition. Circulation 2004; 109;433-438.

6. Alberti KG, Zimmet P, Shaw J. Metabolic syndrome-a new world-wide definition. A Consensus Statement from the International Diabetes Federation. Diabet Med 2006;23:469-480.

7. Alberti KG, Zimmet PZ. Definition, diagnosis and classification of diabetes mellitus and its complications. Part 1: diagnosis and classification of diabetes mellitus provisional report of a WHO consultation. Diabet Med 1998; 15:539-553.

8. Balkau B, Charles MA. Comment on the provisional report from the WHO consultation. European Group for the Study of Insulin Resistance (EGIR). Diabet Med 1999; 16:442-443.

9. Genuth S, Alberti KG, Bennett P, et, al. Follow-up report on the diagnosis of diabetes mellitus. Diabetes Care 2003; 26:3160-3167.

10. Executive Summary of The Third Report of The National Cholesterol Education Program (NCEP) Expert Panel on Detection, Evaluation, and Treatment of High Blood Cholesterol in Adults (Adult Treatment Panel III). JAMA 2001; 285:24862497

11. Al Lawati JA, Mohammed AJ, Al Hinai HQ, Jousilahti P: Prevalence of the metabolic syndrome among Omani adults. Diabetes Care 2003; 26:17811785.

12. Chen CH, Lin KC, Tsai ST, Chou P: Different association of hypertension and insulin-related metabolic syndrome between men and women in 8437 nondiabetic Chinese. Am J Hypertens 2000; 13:846-853.

13. Ford ES, Giles WH, Dietz WH. Prevalence of the Metabolic Syndrome Among US Adults Findings From the Third National Health and Nutrition Examination Survey. JAMA 2002; 287:356-359

14. Isomaa B, Almgren P, Tuomi T, et, al. Cardiovascular Morbidity and Mortality Associated With the Metabolic Syndrome. Diabetes Care 2001; 24:683689

15. Lim S, Park KS, Lee HK, Cho S. Changes in the Characteristics of Metabolic Syndrome in Korea Over the Period 1998-2001 as Determined by Korean National Health and Nutrition Examination Surveys. Diabetes Care 2005; 28:1810-1812. 